\title{
Genetic background of methane emission by Dutch Holstein Friesian cows measured with infrared sensors in automatic milking systems
}

\author{
S. van Engelen, ${ }^{*}{ }^{1}$ H. Bovenhuis, $†$ P. P. J. van der Tol, $\ddagger$ and M. H. P. W. Visker ${ }^{*} \dagger$ \\ *Top Institute Food and Nutrition, PO Box 557, 6700 AN, Wageningen, the Netherlands \\ †Wageningen University \& Research, Animal Breeding and Genomics, PO Box 338, $6700 \mathrm{AH}$, Wageningen, the Netherlands \\ fLely Industries NV, Cornelis van der Lelylaan 1, 3147 PB Maassluis, the Netherlands
}

\section{ABSTRACT}

International environmental agreements have led to the need to reduce methane emission by dairy cows. Reduction could be achieved through selective breeding. The aim of this study was to quantify the genetic variation of methane emission by Dutch Holstein Friesian cows measured using infrared sensors installed in automatic milking systems (AMS). Measurements of $\mathrm{CH}_{4}$ and $\mathrm{CO}_{2}$ on 1,508 Dutch Holstein Friesian cows located on 11 commercial dairy farms were available. Phenotypes per AMS visit were the mean of $\mathrm{CH}_{4}$, mean of $\mathrm{CO}_{2}$, mean of $\mathrm{CH}_{4}$ divided by mean of $\mathrm{CO}_{2}$, and their $\log _{10}$-transformations. The repeatabilities of the $\log _{10}$-transformated methane phenotypes were 0.27 for $\mathrm{CH}_{4}, 0.31$ for $\mathrm{CO}_{2}$, and 0.14 for the ratio. The $\log _{10^{-}}$ transformated heritabilities of these phenotypes were 0.11 for $\mathrm{CH}_{4}, 0.12$ for $\mathrm{CO}_{2}$, and 0.03 for the ratio. These results indicate that measurements taken using infrared sensors in AMS are repeatable and heritable and, thus, could be used for selection for lower $\mathrm{CH}_{4}$ emission. Furthermore, it is important to account for farm, AMS, day of measurement, time of day, and lactation stage when estimating genetic parameters for methane phenotypes. Selection based on $\log _{10}$-transformated $\mathrm{CH}_{4}$ instead of the ratio would be expected to give a greater reduction of $\mathrm{CH}_{4}$ emission by dairy cows.

Key words: methane emission, dairy cow, AMS, nondispersive infrared sensor

\section{INTRODUCTION}

Agriculture contributes $24 \%$ of the total global greenhouse gas emissions (IPCC, 2014). The single largest pollution source within agriculture is enteric fermentation (i.e., the breakdown of feed in the rumen that results in the production of $\mathrm{CH}_{4}$; Gerber et al.,

Received July 5, 2017

Accepted November 21, 2017.

${ }^{1}$ Corresponding author: sabine.vanengelen@wur.nl
2013). Approximately $8 \%$ of the worldwide agricultural greenhouse gas emissions originate from enteric $\mathrm{CH}_{4}$ emissions by dairy cows (FAOSTAT, 2012; FAO, 2014), showing the impact of dairy production on global warming. In December 2015, agreements were made in Paris between 195 countries to tackle climate change and keep global warming firmly below $2^{\circ} \mathrm{C}$ (UNCCC, 2015). These agreements have further emphasized the importance of the reduction of $\mathrm{CH}_{4}$ emission by dairy cows.

Reduction of $\mathrm{CH}_{4}$ emission by dairy cows can be achieved through a combination of mitigation strategies comprising dietary, microbial, management, and breeding strategies (Cottle et al., 2011; Hristov et al., 2013). Selective breeding has the advantage of giving a cumulative, permanent, and long-term reduction of $\mathrm{CH}_{4}$ emission. An example of breeding for reduced $\mathrm{CH}_{4}$ is the reduction of $13 \%$ of $\mathrm{CH}_{4} / \mathrm{kg}$ of milk in Dutch dairy cattle that has been realized from 1990 to 2010 by selection for higher milk production (Vellinga et al., 2011). A further reduction of $\mathrm{CH}_{4}$ emission through selective breeding is wanted and requires quantification of possible genetic variation in $\mathrm{CH}_{4}$ emission.

To quantify possible genetic variation in $\mathrm{CH}_{4}$ emission, $\mathrm{CH}_{4}$ emission needs to be measured on large numbers of individual cows. One of the measurement methods could be infrared sensors installed in automatic milking systems (AMS). The infrared sensor samples the breath of the cows present in the AMS and measures $\mathrm{CH}_{4}$ and $\mathrm{CO}_{2}$ concentration continuously. An advantage of this system is that cows visit the AMS several times per day, and these repeated visits ensure repeated measurements of the same cow over the day and over time (Garnsworthy et al., 2012a). Furthermore, sensors can easily be moved from one AMS to another and, thus, provide the opportunity to measure individual $\mathrm{CH}_{4}$ emission on large numbers of cows.

Previous studies have shown that $\mathrm{CH}_{4}$ measurements based on infrared sensors in AMS are repeatable. Lassen et al. (2012) summarized $\mathrm{CH}_{4}$ measurements per AMS visit by taking the mean of $\mathrm{CH}_{4}$, the mean of $\mathrm{CO}_{2}$, and the mean of the ratio between $\mathrm{CH}_{4}$ and $\mathrm{CO}_{2}$; 
repeatabilities ranged between 0.22 and 0.46 for 50 Holstein cows and 43 Jersey cows. Bell et al. (2014b) found a repeatability of 0.74 for mean of $\mathrm{CH}_{4}$ per AMS visit for 36 Holstein-Friesian cows. These repeatabilities illustrate that infrared sensors in AMS could provide the repeatable measurements on individual cows that are needed to quantify possible genetic variation in $\mathrm{CH}_{4}$ emission.

These $\mathrm{CH}_{4}$ phenotypes can be influenced by farm conditions (Bell et al., 2014a), hour of the day (Garnsworthy et al., 2012b), and week of lactation (Lassen et al., 2016); therefore, these effects were studied. Farm conditions can affect $\mathrm{CH}_{4}$ emission via the differences in feed regimens between farms (Bell et al., 2014a; Hammond et al., 2016). Hour of the day can influence $\mathrm{CH}_{4}$ emission, as cow behavior, time after feeding, and ambient conditions change throughout the day (Garnsworthy et al., 2012b; Lassen et al., 2012; Bell et al., 2014b). Week of lactation can affect $\mathrm{CH}_{4}$ emission, as the amount and composition of feed varies throughout lactation (Garnsworthy et al., 2012b; Bell et al., 2014a; Lassen and Løvendahl, 2016).

Repeated measurements obtained from infrared sensors can be used to estimate the variation in $\mathrm{CH}_{4}$ emission between cows. Lassen and Løvendahl (2016) found genetic variation in $\mathrm{CH}_{4}$ emission that was summarized in several phenotypes. The heritabilities ranged between 0.16 and 0.21 , providing support for the use of $\mathrm{CH}_{4}$ concentrations measured using infrared sensors in AMS to decrease $\mathrm{CH}_{4}$ emission through selective breeding.

The aim of our study was to quantify the genetic variation of $\mathrm{CH}_{4}$ emission by Dutch dairy cows measured using infrared sensors installed in AMS. The data set comprised $\mathrm{CH}_{4}$ and $\mathrm{CO}_{2}$ measurements taken with infrared sensors on Dutch Holstein Friesian cows located on commercial dairy farms. Measurements were summarized into different $\mathrm{CH}_{4}$ phenotypes per AMS visit and repeatability and heritability were calculated for these phenotypes.

\section{MATERIALS AND METHODS}

\section{Ethical Statement}

This research was accredited by the animal experimentation committee of Wageningen University and Research and the central committee animal trials under application number 2013085 and trial code 2013097.

\section{Methane Sensor}

Methane phenotypes were measured using sensors. These sensors were tested in climate respiration cham- bers (CRC) before they were installed on commercial farms. In this test, $\mathrm{CH}_{4}$ emissions of 20 individual Holstein Friesian cows were recorded in CRC for 3 consecutive days and, simultaneously, by the sensor. In the $\mathrm{CRC}, \mathrm{CH}_{4}$ and $\mathrm{CO}_{2}$ were measured every $12.5 \mathrm{~min}$ as described by Heetkamp et al. (2015). The sensors were gas analyzers (SenseAir LPL $\mathrm{CH}_{4} / \mathrm{CO}_{2}$, Rise Acreo, Stockholm, Sweden) that were installed in line with the cow's nostrils when standing and facing forward. Air was drawn through the instrument at $1 \mathrm{~L} / \mathrm{min} ; \mathrm{CH}_{4}$ and $\mathrm{CO}_{2}$ concentrations were measured continuously using a nondispersive infrared (NDIR) technique and logged twice per second. Phenotypes were defined as $\mathrm{CH}_{4}$ production (L/d) from $\mathrm{CRC} ; \mathrm{CH}_{4}$ concentration (ppm) from sensor; and $\mathrm{CH}_{4}: \mathrm{CO}_{2}$ ratio from sensor.

\section{Data}

Methane and $\mathrm{CO}_{2}$ concentrations (ppm) were measured on 1,508 primiparous and multiparous dairy cows from 11 commercial farms in the Netherlands. On 9 of these farms, cows were fed in the morning, whereas on 1 farm cows were fed in the evening. In addition, some farms had automatic feed pushers that compiled the feed continuously during the day, and 1 farm had an automatic feeder that fed the cows freshly mixed feed up to 30 times a day. Furthermore, cows on some farms could graze during the day whereas cows on other farms were kept indoors. More than $85 \%$ of the cows were at least $7 / 8$ Holstein Friesian. Measurements were taken during milking in AMS (Lely Astronaut A4, Lely Industries NV, Maassluis, the Netherlands) using NDIR sensors. A total of 4 sensors were used to collect all data by installing them consecutively in different AMS. Measurements were taken in a total of 23 AMS, 1 to 4 AMS per farm, between November 2013 and March 2016. The data from these sensors were linked to the data from the AMS to obtain the identification numbers (ID) of the cows and, subsequently, additional animal information, such as week of lactation. The data of the sensors were aligned to the AMS visits as both were recorded on different devices. The alignment between these devices was based on the pattern of AMS visits (i.e., duration and order of AMS visits and the time between the AMS visits). This pattern was aligned in such a way that $\mathrm{CH}_{4}$ and $\mathrm{CO}_{2}$ concentrations were highest during AMS visits and lowest in between AMS visits. After alignment, the ID of the cows were used to link sensor data to data from the cooperative cattle improvement organization CRV (Arnhem, the Netherlands) to obtain the pedigree. The pedigree was traced back 2 generations, resulting in 4,214 animals in the pedigree. 


\section{Data Editing}

Data from the sensors and AMS were edited based on several conditions. The first condition was that only data from days with sensor measurements for at least $30 \%$ of the day were kept. Days with less than $30 \%$ data were mostly without data or the data present were fragmentary; therefore, these days were discarded. The number of days with measurements ranged from 10 up to 81 per AMS. The second condition was that AMS visits should last at least $90 \mathrm{~s}$; AMS visits shorter than $90 \mathrm{~s}$ were removed from the data set. Removing AMS visits shorter than $90 \mathrm{~s}$ ensured that most AMS visits that did not result in a milking, and would, thus, not provide a steady measurement, were removed from the data set. The third condition was that the ID of the cow visiting the AMS should be known; AMS visits without cow ID were removed from the data set, as these could not be linked to the pedigree. The fourth condition was that week of lactation of the cow visiting the AMS should be known and cows should be between 1 and $60 \mathrm{wk}$ in lactation. The fifth condition was that AMS visits with missing $\mathrm{CH}_{4}$ phenotypes (see phenotypes) or missing model effects (see model 1) were removed from the data set. The sixth and last condition was that each cow should have at least 4 AMS visits. After editing, a total of 129,900 AMS visits on 1,508 dairy cows that had on average 86 AMS visits (range $=4-295$ AMS visits) were available for analysis. The number of cows ranged between 62 and 224 per farm.

The AMS visits that had a standardized residual effect $>3.5$ based on model 1 for mean and log-transformed $\mathrm{CH}_{4}$, mean and log-transformed $\mathrm{CO}_{2}$, and mean and log-transformed ratio of $\mathrm{CH}_{4}$ to $\mathrm{CO}_{2}$ were considered outliers and were removed. After removal of the outliers, the data set consisted of 123,369 AMS visits from 1,508 dairy cows. This data set was used to estimate the variance components and genetic parameters.

\section{Phenotypes}

The $\mathrm{CH}_{4}$ and $\mathrm{CO}_{2}$ measurements were summarized per AMS visit into 6 phenotypes. To correct for the background levels of $\mathrm{CH}_{4}$ and $\mathrm{CO}_{2}$ in the barn, offsets for $\mathrm{CH}_{4}$ and $\mathrm{CO}_{2}$ were calculated per AMS visit. The background levels of $\mathrm{CH}_{4}$ were assumed to be $0 \mathrm{ppm}$ and the offset for $\mathrm{CH}_{4}$ was the mean of the 10 lowest values for $\mathrm{CH}_{4}$ in a specific AMS visit. As the background levels of $\mathrm{CO}_{2}$ were assumed to be $400 \mathrm{ppm}$, the offset for $\mathrm{CO}_{2}$ was the mean of the lowest 10 values for $\mathrm{CO}_{2}$ minus 400. The $\mathrm{CH}_{4}$ offset was subtracted from the individual (twice per second) $\mathrm{CH}_{4}$ measurements during a specific AMS visit and the $\mathrm{CO}_{2}$ offset was subtracted from the individual $\mathrm{CO}_{2}$ measurements. After adjustment for the offsets, the methane phenotypes were calculated. The first phenotype was the mean of $\mathrm{CH}_{4}$ per AMS visit $\left(\mathbf{C H}_{4} \mathbf{m}\right)$; the second phenotype was the mean of $\mathrm{CO}_{2}$ per AMS visit $\left(\mathbf{C O}_{2} \mathbf{m}\right)$. The third phenotype was based on the ratio $\left(\mathrm{CH}_{4} / \mathrm{CO}_{2}\right)$ per AMS visit and is calculated as the mean of $\mathrm{CH}_{4}$ divided by the mean $\mathrm{CO}_{2}$ per AMS visit (RATm). The residuals of the traits based on model 1 were not normally distributed. For example, the residuals of $\mathrm{CH}_{4} \mathrm{~m}$ showed a thicker and longer right tail (kurtosis $=3.24)$. Therefore, phenotypes were $\log _{10}$-transformated, and after transformation residuals became normally distributed (kurtosis of $\log _{10}$-transformed $\mathrm{CH}_{4} \mathrm{~m}=0.55$ ). These $\log _{10}$-transformations resulted in the fourth phenotype $\left[\log _{10}\left(\mathrm{CH}_{4} \mathrm{~m}\right)\left(\mathbf{C H}_{4} \mathbf{l}\right)\right]$, fifth phenotype $\left[\log _{10}\left(\mathrm{CO}_{2} \mathrm{~m}\right)\right.$ $\left.\left(\mathbf{C O}_{2} \mathbf{l}\right)\right]$, and sixth phenotype $\left[\log _{10}(\mathrm{RATm})(\mathbf{R A T l})\right]$ Furthermore, milk yield in kilograms per AMS visit was included as a general trait.

\section{Data Analysis}

Variance components of the phenotypes were estimated with ASReml 4.1 (Gilmour et al., 2015) using the model

$$
\begin{gathered}
\mathrm{Y}_{\mathrm{ijklm}}=\mu+\text { DayAMS }_{\mathrm{i}}+\text { Lactationweek }_{\mathrm{j}}+\text { Hour } \\
\times \text { Farm }_{\mathrm{k}}+\text { Animal }_{\mathrm{l}}+\text { Permanent }_{\mathrm{m}}+\mathrm{e}_{\mathrm{ijklm}},
\end{gathered}
$$

where $\mathrm{Y}_{\mathrm{ijklm}}$ is the dependent variable $\left(\mathrm{CH}_{4} \mathrm{~m}, \mathrm{CO}_{2} \mathrm{~m}\right.$, RATm, $\mathrm{CH}_{4} \mathrm{l}, \mathrm{CO}_{2} \mathrm{l}$, RATl, or milk yield); $\mu$ is the mean; DayAMS $\mathrm{S}_{\mathrm{i}}$ is the combined effect of day of measurementfarm of measurement, AMS of measurement, and sensor of measurement (DayAMS; 991 levels); Lactationweek $_{\mathrm{j}}$ is the fixed effect of week of lactation (60 levels); Hour $\times \mathrm{Farm}_{\mathrm{k}}$ is the fixed interaction of hour of the day (24 levels) and farm of measurement (11 levels); Animal $_{1}$ is the random additive genetic effect of animal $\left[\sim N\left(0, \mathbf{A} \sigma_{\text {animal }}^{2}\right)\right]$, with additive genetic relationship matrix $\mathbf{A}$ and additive genetic variance $\sigma_{\text {animal }}^{2}$; Permanent $_{m}$ is the random permanent environmental effect $\left[\sim N\left(0, \mathbf{I} \sigma_{\text {permanent }}^{2}\right)\right]$, with identity matrix $\mathbf{I}$ and permanent environmental variance $\sigma_{\text {permanent }}^{2}$; and $\mathrm{e}_{\mathrm{ijklm}}$ is the random error effect $\left[\sim N\left(0, \mathbf{I} \sigma_{\text {error }}^{2}\right)\right]$, with identity matrix $\mathbf{I}$ and residual variance $\sigma_{\text {error }}^{2}$.

\section{Measurement Period}

For analysis, all data available for each cow were used, ranging from 1 to $81 \mathrm{~d} /$ cow. To study the effect of 
length of measurement period a subset of the data were used consisting of data from 1 AMS on 1 farm during 50 consecutive days from December 2015 to February 2016. The measurement period lengths that were tested were $3,5,10,20$, and 30 consecutive days. For each of these lengths, 5 individual data sets with that length in consecutive days were created by random sampling from the data set of $50 \mathrm{~d}$ (e.g., 5 data sets containing 30 consecutive days). Data sets of the same measurement period length were sometimes partially overlapping. Repeatabilities were calculated for each measurement period data set, and repeatabilities and their standard errors were averaged over the 5 data sets for each measurement period length.

\section{Genetic Parameters}

The repeatability was calculated as

$$
\text { Repeatability }=\frac{\sigma_{\text {animal }}^{2}+\sigma_{\text {permanent }}^{2}}{\sigma_{\text {animal }}^{2}+\sigma_{\text {permanent }}^{2}+\sigma_{\text {error }}^{2}},
$$

with additive genetic variance $\sigma_{\text {animal }}^{2}$, permanent environmental variance $\sigma_{\text {permanent }}^{2}$, and residual variance $\sigma_{\text {error }}^{2}$. The heritability $\left(h^{2}\right)$ was calculated as

$$
h^{2}=\frac{\sigma_{\text {animal }}^{2}}{\sigma_{\text {animal }}^{2}+\sigma_{\text {permanent }}^{2}+\sigma_{\text {error }}^{2}} .
$$

We presented the descriptive statistics on all 6 phenotypes, but the genetic parameters of only the $\log _{10^{-}}$ transformed phenotypes were shown. As the residuals of the untransformed phenotypes were not normally distributed, this could affect the results found for these genetic parameters. Effects of the model parameters were presented on the untransformed phenotypes as these effects are then easier to interpret.

The accuracy of the breeding value for $\mathrm{CH}_{4}$ emission for a cow was calculated as

$$
\sqrt{\frac{m h^{2}}{(m-1) t+1}}
$$

where $m$ is the number of repeated sensor measurements in an AMS, $h^{2}$ is the heritability, and $t$ is the repeatability. The accuracy of breeding value for $\mathrm{CH}_{4}$ for a bull with half-sib daughters was calculated as

$$
\sqrt{\frac{n x^{2}}{(n-1) x^{2}+4}}
$$

where $n$ is the number of half-sib daughters and $x$ is the accuracy of the breeding value of the daughters with 25 repeated sensor measurements each.

\section{RESULTS}

\section{Methane Sensor Test}

During the test, the repeatabilities of $\mathrm{CH}_{4}$ production $(\mathrm{L} / \mathrm{d}), \mathrm{CH}_{4}$ concentration $(\mathrm{ppm})$ and $\mathrm{CH}_{4}: \mathrm{CO}_{2}$ ratio were calculated using data averaged per cow per day. Repeatability of $\mathrm{CH}_{4}$ production obtained from CRC measurements was $0.87(\mathrm{SE}=0.04)$, repeatability of $\mathrm{CH}_{4}$ concentration obtained from sensor measurements was $0.90(\mathrm{SE}=0.04)$, and repeatability of $\mathrm{CH}_{4}: \mathrm{CO}_{2}$ ratio obtained from sensor measurements was 0.94 ( $\mathrm{SE}$ $=0.02$ ) . The correlation between $\mathrm{CH}_{4}$ production obtained from $\mathrm{CRC}$ and $\mathrm{CH}_{4}$ concentration obtained from sensor was $0.71(\mathrm{SE}=0.10)$. The correlation between $\mathrm{CH}_{4}$ production obtained from $\mathrm{CRC}$ and $\mathrm{CH}_{4}: \mathrm{CO}_{2}$ ratio obtained from sensor was $0.49(\mathrm{SE}=0.18)$.

\section{Descriptive Statistics}

Descriptive statistics on the 6 methane phenotypes and on milk production per AMS visit are represented in Table 1. After the $\log _{10}$-transformation, the means and standard deviations of $\mathrm{CH}_{4} \mathrm{~m}$ and $\mathrm{CO}_{2} \mathrm{~m}$ decreased,

Table 1. Descriptive statistics of phenotypes on $\mathrm{CH}_{4}$ and $\mathrm{CO}_{2}$ measured with nondispersive infrared (NDIR) sensors in automatic milking systems (AMS) on 1,508 Dutch dairy cows (123,369 AMS visits)

\begin{tabular}{lcccc}
\hline Trait & Mean & SD & Minimum & Maximum \\
\hline $\mathrm{CH}_{4}$ mean $(\mathrm{ppm})$ & 254 & 230 & 11 & 2,073 \\
$\mathrm{CH}_{4} \log ^{1}(\mathrm{ppm})$ & 2.25 & 0.37 & 1.04 & 3.32 \\
$\mathrm{CO}_{2}$ mean $(\mathrm{ppm})$ & 1,443 & 681 & 408 & 9,054 \\
$\mathrm{CO}_{2} \log ^{1}(\mathrm{ppm})$ & 3.11 & 0.20 & 2.61 & 3.96 \\
$\mathrm{CH}_{4}: \mathrm{CO}_{2}$ ratio mean & 0.17 & 0.12 & 0.01 & 0.87 \\
$\mathrm{CH}_{4}: \mathrm{CO}_{2}$ ratio $\log ^{1}$ & -0.87 & 0.27 & -1.92 & -0.06 \\
Milk $^{2}(\mathrm{~kg})$ & 10.8 & 3.4 & 0.00 & 36.50 \\
\hline
\end{tabular}

${ }^{1} \log _{10}$-transformed phenotypes.

${ }^{2}$ Milk production per AMS visit. 
whereas the mean and standard deviation increased in an absolute sense for RATm. A milk yield of $0 \mathrm{~kg}$ for 619 AMS visits illustrates that during these AMS visits the cows were not milked by the AMS. These AMS visits were still present in the data set, despite removing AMS visits shorter than $90 \mathrm{~s}$. We considered any AMS visit longer than $90 \mathrm{~s}$ suitable for $\mathrm{CH}_{4}$ and $\mathrm{CO}_{2}$ measurements, irrespective if the cow was being milked during that visit.

\section{Effect of Hour of the Day on Methane Emission}

In general, the effect of hour of the day on $\mathrm{CH}_{4} \mathrm{~m}$, as obtained from model 1, was lower during the night and higher during the day. This general pattern showed variation between farms, as demonstrated by farms A and B in Figure 1. Farm A showed 2 distinct peaks in $\mathrm{CH}_{4} \mathrm{~m}$ during the day: the first peak around $0900 \mathrm{~h}$ and the second peak around $2000 \mathrm{~h}$. Farm B showed a strong increase in $\mathrm{CH}_{4} \mathrm{~m}$ during the day compared with the night. Both types of patterns were present in the data set, but most farms had a pattern similar to that of farm A.

\section{Effect of Week of Lactation on Methane Emission}

The effect of week of lactation on $\mathrm{CH}_{4} \mathrm{~m}$, as obtained from model 1, for the first $50 \mathrm{wk}$ of lactation is presented in Figure 2. The effect of week of lactation on $\mathrm{CH}_{4} \mathrm{~m}$ increased rapidly during the first $12 \mathrm{wk}$ of lactation. After this strong increase, the effect of week of lactation on $\mathrm{CH}_{4} \mathrm{~m}$ remained relatively constant until

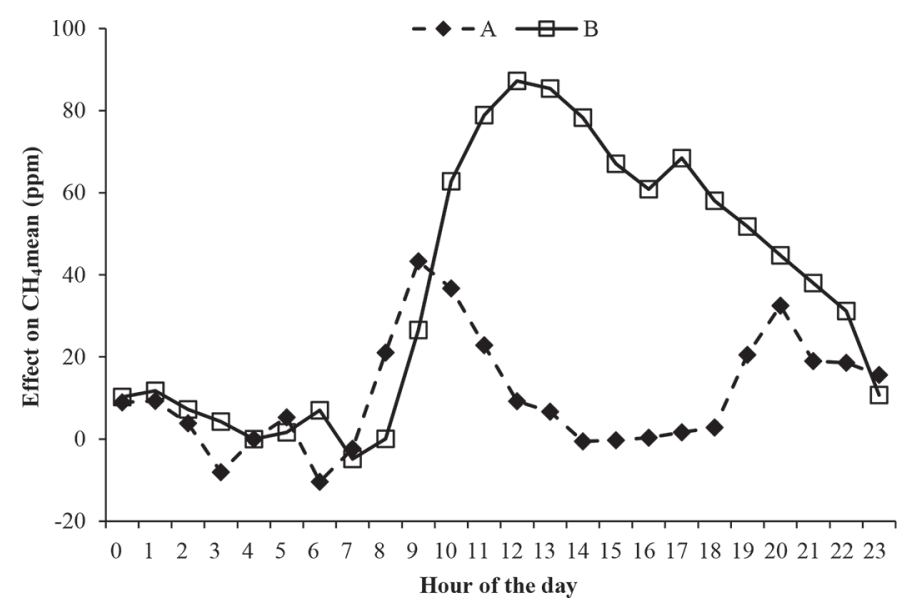

Figure 1. Effect of hour of the day on $\mathrm{CH}_{4}$ mean (ppm) measured with nondispersive infrared (NDIR) sensors in automatic milking systems (AMS) on 1,508 Dutch dairy cows. The figure shows 2 representative farms $(\mathrm{A}=5,554 \mathrm{AMS}$ visits; $\mathrm{B}=20,458 \mathrm{AMS}$ visits $)$. The effect of $\mathrm{h} 4$ was set to zero for both farms to enable comparison and the other effects are expressed relative to $\mathrm{h} 4$.
35 wk in lactation and decreased gradually thereafter. Between wk 12 and 35, the effect of lactation week accounted for 3 to $7 \%$ of the variation in the mean of $\mathrm{CH}_{4} \mathrm{~m}$.

\section{Genetic Parameters for Methane Emission}

Repeatabilities and heritabilities of the $\log _{10}$-transformated methane phenotypes and milk production are presented in Table 2 . The repeatabilities ranged between 0.14 and 0.31 for the methane phenotypes, were similar for $\mathrm{CH}_{4} \mathrm{l}$ and $\mathrm{CO}_{2} \mathrm{l}$, and were lower for RATl. The heritabilities were lower than the repeatabilities and ranged between 0.03 and 0.12 for the methane phenotypes. Heritabilities were similar for $\mathrm{CH}_{4} \mathrm{l}$ and $\mathrm{CO}_{2} \mathrm{l}$ and were lower for RATl. Milk yield per AMS visit had a higher repeatability (0.45) and heritability (0.17) than the methane phenotypes; standard errors of the repeatabilities and heritabilities were between 0.005 and 0.03 .

The accuracy of the breeding value for $\mathrm{CH}_{4}$ emission expressed as $\mathrm{CH}_{4} \mathrm{l}$ for a cow based on 25 repeated sensor measurements in an AMS was 0.61. For a bull with 25 daughters, where each daughter has 25 repeated sensor measurements, the accuracy of the breeding value for $\mathrm{CH}_{4}$ emission was 0.85 .

\section{Effect of Measurement Period}

The average repeatabilities and standard error of each measurement period length are presented in Table 3. All 3 methane phenotypes showed higher repeatabilities

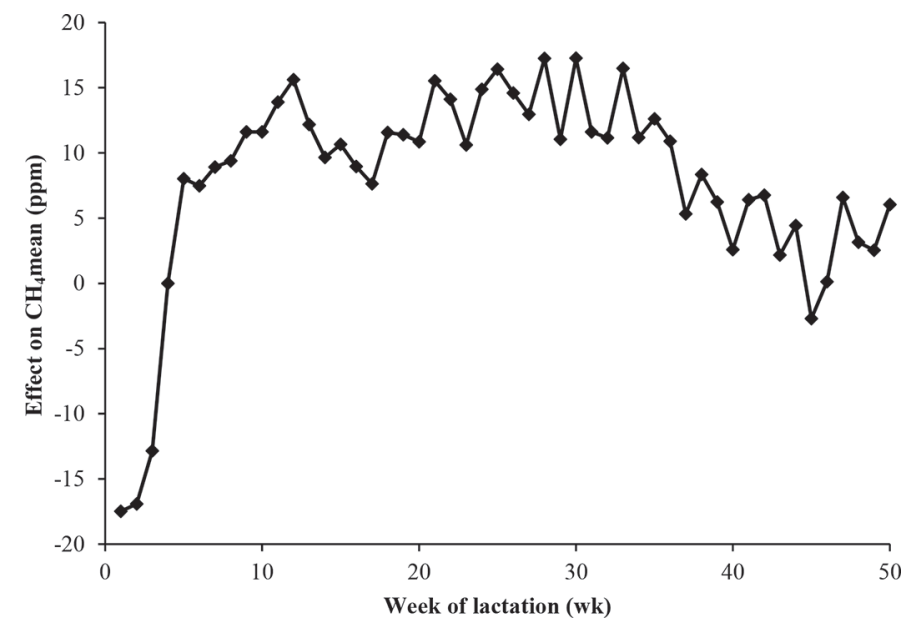

Figure 2. Effect of week of lactation on $\mathrm{CH}_{4}$ mean (ppm) measured with nondispersive infrared (NDIR) sensors in automatic milking systems (AMS) on 1,508 Dutch dairy cows (123,369 AMS visits). The effect of wk 4 of lactation was set to zero and the other effects are expressed relative to wk 4 . 
Table 2. Repeatabilities and heritabilities of phenotypes on $\mathrm{CH}_{4}$ and $\mathrm{CO}_{2}$ measured with nondispersive infrared (NDIR) sensors in automatic milking systems (AMS) on 1,508 Dutch dairy cows $(123,369$ AMS visits) ${ }^{1}$

\begin{tabular}{lcc}
\hline Trait & Repeatability & Heritability \\
\hline $\mathrm{CH}_{4} \log ^{2}(\mathrm{ppm})$ & $0.27(0.008)$ & $0.11(0.02)$ \\
$\mathrm{CO}_{2} \log ^{2}(\mathrm{ppm})$ & $0.31(0.009)$ & $0.12(0.02)$ \\
$\mathrm{CH}_{4}: \mathrm{CO}_{2}$ ratio $\log ^{2}$ & $0.14(0.005)$ & $0.03(0.01)$ \\
$\mathrm{Milk}^{3}(\mathrm{~kg})$ & $0.45(0.010)$ & $0.17(0.03)$ \\
\hline
\end{tabular}

${ }^{1}$ This table contains the repeatability (repeatability $=\sigma_{\text {animal }}^{2}+$ $\sigma_{\text {permanent }}^{2} / \sigma_{\text {animal }}^{2}+\sigma_{\text {permanent }}^{2}+\sigma_{\text {error }}^{2}$ ) and the heritability (heritability $\left.=\sigma_{\text {animal }}^{2} / \sigma_{\text {animal }}^{2}+\sigma_{\text {permanent }}^{2}+\sigma_{\text {error }}^{2}\right)$ with their respective SE in parentheses, where $\sigma_{\text {animal }}^{2}, \sigma_{\text {permanent }}^{2}$, and $\sigma_{\text {error }}^{2}$ are additive genetic, permanent environmental, and residual variance, respectively.

${ }^{2} \log _{10}$-transformed phenotypes.

${ }^{3}$ Milk production per AMS visit.

in measurement periods longer than $5 \mathrm{~d}$ compared with shorter measurement periods. Measurement periods longer than $10 \mathrm{~d}$ did not lead to further improvements of the repeatabilities. Standard errors decreased with increasing measurement period length, but the largest decrease occurred with the increase in measurement period from 3 to $5 \mathrm{~d}$. Furthermore, repeatabilities of the measurement period of $10 \mathrm{~d}$ were not significantly different from the repeatabilities of the data set with all observations from that specific AMS.

\section{DISCUSSION}

The aim of our study was to quantify the genetic variation in methane phenotypes measured with NDIR sensors in AMS. Methane phenotypes based on sensor measurements of $\mathrm{CH}_{4}$ and $\mathrm{CO}_{2}$ on Dutch dairy cows were both repeatable and heritable. The repeatabilities of these phenotypes ranged between 0.14 and 0.31 . The heritabilities of these phenotypes ranged between 0.03 and 0.12 , indicating genetic variation in these phenotypes.

\section{Methane Sensor Test}

High repeatability of $\mathrm{CH}_{4}$ production obtained from CRC measurements and of $\mathrm{CH}_{4}$ concentration obtained from sensors agree with the literature (Bell et al., 2014b; Donoghue et al., 2016). The high repeatabilities found in the present study demonstrate high consistency between subsequent measurements on the same animal, implying high precision of measurement and suggesting consistent differences between animals. High repeatabilities and moderate correlations demonstrate the potential of the sensor method for the collection of phenotypes on $\mathrm{CH}_{4}$ emission for large numbers of individual animals. Repeatabilities are expected to be lower when installed in AMS because of more variable conditions on the farm. This limitation is most likely compensated by the ability to perform large-scale collection of data on commercial dairy farms. This facilitates repeated measures on a single animal and recording large numbers of animals, both contributing to the accuracy of estimated breeding values.

\section{Methane Phenotypes}

Phenotypes used in our study were measured in parts per million. In the literature, concentration measurements (in ppm) have been transformed to $\mathrm{CH}_{4}$ production $(\mathrm{g} / \mathrm{d})$ using a dilution factor or using $\mathrm{CO}_{2}$ production (Madsen et al., 2010; Garnsworthy et al., 2012a; Lassen and Løvendahl, 2016). These transformations, however, are based on several assumptions, such as a constant $\mathrm{CO}_{2}$ production of a cow throughout the day

Table 3. The average repeatability of phenotypes on $\mathrm{CH}_{4}$ and $\mathrm{CO}_{2}$ measured with nondispersive infrared (NDIR) sensors in automatic milking systems (AMS) on Dutch dairy cows over different measurement period lengths ${ }^{1,2}$

\begin{tabular}{lrccc}
\hline Measurement period & $\mathrm{N}$ & $\mathrm{CH}_{4} \log ^{3}$ & $\mathrm{CO}_{2} \log ^{3}$ & $\mathrm{CH}_{4}: \mathrm{CO}_{2}{\text { ratio } \log ^{3}}^{3}$ \\
\hline Total AMS period & 8,851 & $0.19(0.029)$ & $0.16(0.026)$ & $0.19(0.026)$ \\
$3 \mathrm{~d}$ & 376 & $0.12(0.075)$ & $0.12(0.062)$ & $0.14(0.079)$ \\
$5 \mathrm{~d}$ & 650 & $0.15(0.055)$ & $0.12(0.044)$ & $0.15(0.054)$ \\
$10 \mathrm{~d}$ & 1,295 & $0.22(0.049)$ & $0.17(0.043)$ & $0.22(0.048)$ \\
$20 \mathrm{~d}$ & 2,567 & $0.23(0.040)$ & $0.18(0.034)$ & $0.23(0.038)$ \\
$30 \mathrm{~d}$ & 3,827 & $0.23(0.037)$ & $0.18(0.031)$ & $0.22(0.034)$ \\
$50 \mathrm{~d}$ & 6,296 & $0.22(0.032)$ & $0.16(0.026)$ & $0.21(0.030)$ \\
\hline
\end{tabular}

${ }^{1}$ Per-measurement period length, 5 random samples were taken from the data set of 50 consecutive days, and numbers reported are the average over these 5 random samples. Total AMS period consists of all data from the 1 AMS $(73 \mathrm{~d})$ of which the data set of 50 consecutive days was obtained.

${ }^{2}$ The table contains the measurement period in days, the average number of AMS visit per measurement pe$\operatorname{riod}_{2}(\mathrm{~N})$, and the average repeatability per methane phenotype (repeatability ${ }_{2}=\sigma_{\text {animal }}^{2}+\sigma_{\text {permanent }}^{2} / \sigma_{\text {animal }}^{2}$ $+\sigma_{\text {permanent }}^{2}+\sigma_{\text {error }}^{2}$ ) with their respective average SE in parentheses, where $\sigma_{\text {animal }}^{2}, \sigma_{\text {permanent }}^{2}$, and $\sigma_{\text {error }}^{2}$ are additive genetic, permanent environmental, and residual variance, respectively.

${ }^{3} \log _{10}$-transformed phenotypes. 
that may not always be met. The $\mathrm{CH}_{4}$ production obtained after transformation is affected by the accuracy of these assumptions. For breeding, absolute values are not needed, as it focuses on the relative differences between animals to select the best animals.

Phenotypes similar to those used in our study were also used in other studies (e.g., Madsen et al., 2010; Lassen et al., 2012; Bell et al., 2014b). The absolute values of such similar phenotypes, however, have not been published except for RATm (i.e., the mean of the ratio between $\mathrm{CH}_{4}$ and $\mathrm{CO}_{2}$ ). We included RATm in our study because it was reported in other studies and can be used to quantify methane production (Madsen et al., 2010). The absolute value of RATm in our study was considerably higher than the one reported by Lassen et al. (2012; i.e., 0.17 vs. 0.065). The reason for this difference is unclear, as the absolute values of the underlying traits to RATm (i.e., $\mathrm{CH}_{4} \mathrm{~m}$ and $\mathrm{CO}_{2} \mathrm{~m}$ ) were not reported by Lassen et al. (2012). Breeding, however, does not depend on absolute values, and, therefore, it is expected that the difference in absolute value of RATl compared with the literature would not affect the direction of selection if RATl would be used for selection.

\section{Milk Yield}

Selective breeding for milk yield has led to substantial genetic progress over time. Heritability for milk yield per AMS visit in our study was $0.17(\mathrm{SE}=0.03)$. This heritability is slightly lower than the heritability of 0.24 reported (Mulder et al., 2004) for milk yield per day recorded in AMS. The heritability of $\mathrm{CH}_{4} \mathrm{l}$ was 0.11 $(\mathrm{SE}=0.02)$, which is comparable with the heritability of milk yield per AMS visit. This indicates potential for a reduction in methane emission through selective breeding when using sensor measurements in AMS.

\section{Effect of DayAMS}

The DayAMS effect that was used in the model includes the effects of the day, farm, AMS, and sensor of measurement. These effects could not be disentangled in our study, because most measurements took place on 1 farm at a time, with a single sensor installed per AMS. To study the effect of DayAMS on the methane phenotypes, an additional analysis was performed in which DayAMS was included in model 1 as a random effect instead of as a fixed effect. This analysis showed that the percentage of total variation that was explained by the DayAMS effect was $56 \%$ for $\mathrm{CH}_{4} 1,27 \%$ for $\mathrm{CO}_{2} \mathrm{l}$, and $82 \%$ for RATl. These results indicate that the phenotypes were largely influenced by the DayAMS effect, and illustrates that accounting for the effects of day of measurement, farm, AMS, and sensor is important when analyzing methane phenotypes. Farm conditions that are known to influence $\mathrm{CH}_{4}$ measurements are season, air flow, and barn management (Wu et al., 2016). The large effect of DayAMS agrees with the other studies that acknowledge the effect of farm of measurement and farm conditions on methane measurements (Bell et al., 2014a; Hammond et al., 2016).

\section{Effect of Hour of the Day on Methane Emission}

Hour of the day had a significant effect in our analysis, with a $P$-value below 0.001 when DayAMS was included in model 1 as random. The size of the effect is relatively small compared with the effect of DayAMS. This is in line with previous studies that reported diurnal variation in methane emission, mainly driven by the time of feeding of the cows (Garnsworthy et al., 2012b; Lassen et al., 2012; Bell et al., 2014b). To deal with the rather different feeding strategies of the 11 farms in our study (see Materials and Methods), a farm by hour of the day interaction was included in the model instead of a single hour of the day effect. Not only did the moment of feeding differ between the farms, but also the amount of times the cows were fed and the possibility of grazing. These diverse strategies resulted in hour of the day effects per farm that were different for each farm. Therefore, inclusion of the interaction between hour of the day and farm instead of a single hour of the day effect into the model was preferred to deal with these diverse feeding strategies.

\section{Effect of Week of Lactation on Methane Emission}

Week of lactation had a significant effect in the model, with a $P$-value below 0.001 when DayAMS was included in model 1 as random. The size of the effect is relatively small compared with the effect of DayAMS. As feed composition and intake usually changes throughout lactation, week of lactation can affect $\mathrm{CH}_{4}$ emission (Garnsworthy et al., 2012b; Bell et al., 2014a; Lassen and Løvendahl, 2016). Previous studies also reported effects of lactation stage on methane emission measured in AMS (Garnsworthy et al., 2012b; Bell et al., 2014a; Lassen and Løvendahl, 2016). Similar to our study, these studies found an increase in methane emissions during the first weeks of lactation. The highest level of methane emission was found at around $10 \mathrm{wk}$ of lactation by Lassen and Løvendahl (2016), at $20 \mathrm{wk}$ of lactation by Garnsworthy et al. (2012b), and at 12 wk of lactation in our study. After the initial increase in methane emission per week of lactation, either a stable level of methane emission until $50 \mathrm{wk}$ in lactation was reported (Bell et al., 2014a) or a decrease in methane 
emission per week of lactation was reported (Garnsworthy et al., 2012b; Lassen and Løvendahl, 2016). The extent of this decrease varied between $20 \%$ of the peak methane emission at $50 \mathrm{wk}$ of lactation (Garnsworthy et al., 2012b) and $80 \%$ of the peak methane emission at $44 \mathrm{wk}$ of lactation (Lassen and Løvendahl, 2016). In our study, methane emission decreased with about $33 \%$ of the peak methane emission at 50 wk of lactation. The pattern found in our study is comparable with the patterns found in literature, and the differences in patterns might be explained by many different factors such as the used phenotypes. Our study used $\mathrm{CH}_{4} \mathrm{~m}$ in parts per million as the phenotype whereas other studies used methane in grams per day that was either from the integral area under the peaks of methane emission (Garnsworthy et al., 2012b) or by the ratio between $\mathrm{CH}_{4}$ and $\mathrm{CO}_{2}$ in relation to heat-producing units (Lassen and Løvendahl, 2016). Based on the results of our study and of the literature, inclusion of lactation stage into the model to analyze methane emission is recommended.

\section{Repeatabilities of Methane Phenotypes}

Selective breeding requires a repeatable phenotype for methane emission, and methane phenotypes measured in AMS using infrared sensors could be suitable phenotypes. In our study, repeatabilities of the $\log _{10^{-}}$ transformed methane phenotypes ranged between 0.14 and 0.31 . Other studies have reported repeatabilities of $\mathrm{CH}_{4}$ measured in AMS that ranged between 0.34 for the mean of $\mathrm{CH}_{4}$ and 0.86 for the mean of $\mathrm{CO}_{2}$ (Lassen et al., 2012; Bell et al., 2014b). In general, the repeatabilities found in other studies were higher than the repeatabilities found in our study. Both Lassen et al. (2012) and Bell et al. (2014b) used a model that corrects for diet effects, which might explain the higher repeatabilities found in these studies compared with our study. Repeatabilities found in our study and other studies do confirm that methane measurements by infrared sensors in AMS provide repeatable phenotypes.

\section{Effect of Measurement Period}

Measurement period influenced the repeatabilities found in our study, and other studies have chosen different measurement periods. Bell et al. (2014b) measured $\mathrm{CH}_{4}$ and $\mathrm{CO}_{2}$ for a 35-d period, whereas Lassen et al. (2012) measured for a 3 -d period. The results obtained from our study indicate that repeatabilities (and their $\mathrm{SE}$ ) remained stable in measurement periods of at least 10 consecutive days. In other words, the value of additional repeated measurements beyond $10 \mathrm{~d}$ of measurements on the same individual was close to zero.
Although Lassen et al. (2012) used a shorter measurement period than our study, their reported standard errors are small ( $\mathrm{SE}=0.003-0.006)$. This indicates that the repeatability reported will likely not be affected by increasing the measurement period.

\section{Genetic Parameters for Methane Emission}

The heritabilities of the $\log _{10}$-transformed phenotypes in this study were 0.11 for $\mathrm{CH}_{4} \mathrm{l}, 0.12$ for $\mathrm{CO}_{2} \mathrm{l}$, and 0.03 for RATl. Lassen and Løvendahl (2016) measured methane using infrared sensors in AMS on 3,121 Holstein cows and calculated heritabilities of methane emission. Methane emission calculated using the ratio between $\mathrm{CH}_{4}$ and $\mathrm{CO}_{2}$ (in ppm) gave a heritability of 0.16 , and both $\mathrm{CH}_{4}$ in grams per day and $\mathrm{CH}_{4}$ in grams per kilogram of fat- and protein-corrected milk gave a heritability of 0.21 . These heritabilities were slightly higher compared with the heritabilities of $\mathrm{CH}_{4} \mathrm{l}$ and $\mathrm{CO}_{2} \mathrm{l}$ in our study. The heritability of RATl of our study is considerably lower compared with the other heritabilities. Lassen et al. (2012) used the ratio between $\mathrm{CH}_{4}$ and $\mathrm{CO}_{2}$ to create a more stable phenotype that was less influenced by the position of the head of the cow to the sensor. In our study, however, we found that RATl had relatively more total variation and less genetic variation than $\mathrm{CH}_{4} \mathrm{l}$ and $\mathrm{CO}_{2} \mathrm{l}$. Therefore, based on the results of our study, the use of $\mathrm{CH}_{4} \mathrm{l}$ for selection instead of RATl would be expected to give a greater reduction of methane emission by dairy cows.

The heritability of the phenotypes showed genetic variation in $\mathrm{CH}_{4}$ and $\mathrm{CO}_{2}$ measured using infrared sensors in AMS, indicating that these phenotypes could be used in selective breeding. The reduction in methane emission that could be achieved through selective breeding depends on the genetic variance of methane emission, the intensity of selection, the accuracy of selection, and the relationship between methane emission and the other breeding goal traits. The accuracies of breeding values for methane emission for cows and bulls were 0.61 and 0.85 , respectively. This illustrates that fairly accurate estimates of breeding values for selective breeding can be obtained based on repeated methane measurements on a limited number of daughters per bull.

\section{CONCLUSIONS}

The $\mathrm{CH}_{4} 1, \mathrm{CO}_{2} \mathrm{l}$, and RATl were all repeatable and heritable, but RATl had a lower repeatability and heritability than the other 2 traits. It is recommended to measure $\mathrm{CH}_{4}$ and $\mathrm{CO}_{2}$ on at least 10 consecutive days to maximize repeatabilities of the methane phenotypes. It is important to account for farm, AMS, day 
of measurement, time of day, and lactation stage when estimating genetic parameters for methane phenotypes. The use of $\mathrm{CH}_{4}$ l for selection instead of RATl would be expected to give a greater reduction of methane emission by dairy cows.

\section{ACKNOWLEDGMENTS}

The authors acknowledge the 11 farmers for their input and collaboration with the project and Jan Kortmann (Lely Industries NV, Maassluis, the Netherlands) for his technical assistance.

\section{REFERENCES}

Bell, M. J., S. L. Potterton, J. Craigon, N. Saunders, R. H. Wilcox, M. Hunter, J. R. Goodman, and P. C. Garnsworthy. 2014a. Variation in enteric methane emissions among cows on commercial dairy farms. Animal 8:1540-1546.

Bell, M. J., N. Saunders, R. H. Wilcox, E. M. Homer, J. R. Goodman, J. Craigon, and P. C. Garnsworthy. 2014b. Methane emissions among individual dairy cows during milking quantified by eructation peaks or ratio with carbon dioxide. J. Dairy Sci. 97:6536-6546.

Cottle, D. J., J. V. Nolan, and S. G. Wiedemann. 2011. Ruminant enteric methane mitigation: A review. Anim. Prod. Sci. 51:491-514.

Donoghue, K. A., T. Bird-Gardiner, P. F. Arthur, R. M. Herd, and R. S. Hegarty. 2016. Repeatability of methane emission measurements in australian beef cattle. Anim. Prod. Sci. 56:213-217.

FAO. 2014. Food and Agriculture Statistical Yearbook 2014. Europe and Central Asia Food and Agriculture. Food and Agriculture Organization of the United Nations Regional Office for Europe and Central Asia, Budapest, Hungary.

FAOSTAT. 2012. FAOSTAT Emission Database. Accessed Feb. 26, 2016. http://www.fao.org/faostat/en/\#home.

Garnsworthy, P. C., J. Craigon, J. H. Hernandez-Medrano, and N. Saunders. 2012a. On-farm methane measurements during milking correlate with total methane production by individual dairy cows. J. Dairy Sci. 95:3166-3180.

Garnsworthy, P. C., J. Craigon, J. H. Hernandez-Medrano, and N. Saunders. 2012b. Variation among individual dairy cows in methane measurements made on farm during milking. J. Dairy Sci. 95:3181-3189.

Gerber, P. J., H. Steinfeld, B. Henderson, A. Mottet, C. Opio, J. Dijkman, A. Falcucci, and G. Tempio. 2013. Tackling Climate Change Through Livestock - A Global Assessment of Emissions and Mitigation Opportunities. Food and Agriculture Organization of the United Nations, Rome, Italy.
Gilmour, A. R., B. J. Gogel, B. R. Cullis, S. J. a. Welham, and R. Thompson. 2015. Asreml User Guide Release 4.1 Structural Specification. VSN International Ltd., Hemel Hempstead, UK.

Hammond, K. J., L. A. Crompton, A. Bannink, J. Dijkstra, D. R Yáñez-Ruiz, P. O'Kiely, E. Kebreab, M. A. Eugène, Z. Yu, K. J. Shingfield, A. Schwarm, A. N. Hristov, and C. K. Reynolds. 2016. Review of current in vivo measurement techniques for quantifying enteric methane emission from ruminants. Anim. Feed Sci. Technol. 219:13-30.

Heetkamp, M. J. W., S. J. J. Alferink, T. Zandstra, P. Hendriks, H. d. Brand, and W. J. J. Gerrits. 2015. Design of climate respiration chambers, adjustable to the metabolic mass of subjects. Pages 35-56 in Indirect Calorimetry. Wageningen Academic Publishers, Wageningen, the Netherlands.

Hristov, A. N., T. Ott, J. Tricarico, A. Rotz, G. Waghorn, A. Adesogan, J. Dijkstra, F. Montes, J. Oh, E. Kebreab, S. J. Oosting, P. J. Gerber, B. Henderson, H. P. S. Makkar, and J. Firkins. 2013. Special topics - Mitigation of methane and nitrous oxide emissions from animal operations: III. A review of animal management mitigation options. J. Anim. Sci. 91:5095-5113.

IPCC. 2014. Climate change 2014: Synthesis report. Contribution of Working Groups I, II and III to the Fifth Assessment Report of the Intergovermental Panel on Climate Change. R. K. Pachauri and L. A. Meyer, ed. IPCC, Geneva, Switzerland.

Lassen, J., and P. Løvendahl. 2016. Heritability estimates for enteric methane emissions from Holstein cattle measured using noninvasive methods. J. Dairy Sci. 99:1959-1967.

Lassen, J., P. Lovendahl, and J. Madsen. 2012. Accuracy of noninvasive breath methane measurements using Fourier transform infrared methods on individual cows. J. Dairy Sci. 95:890-898.

Lassen, J., N. A. Poulsen, M. K. Larsen, and A. J. Buitenhuis. 2016. Genetic and genomic relationship between methane production measured in breath and fatty acid content in milk samples from Danish Holsteins. Anim. Prod. Sci. 56:298-303.

Madsen, J., B. S. Bjerg, T. Hvelplund, M. R. Weisbjerg, and P. Lund. 2010. Methane and carbon dioxide ratio in excreted air for quantification of the methane production from ruminants. Livest. Sci. 129:223-227.

Mulder, H. A., A. F. Groen, G. De Jong, and P. Bijma. 2004. Genotype $\times$ environment interaction for yield and somatic cell score with automatic and conventional milking systems. J. Dairy Sci. $87: 1487-1495$.

UNCCC. 2015. United nations conference on climate change. Accessed Feb. 26, 2016. http://www.cop21paris.org.

Vellinga, T. V., A. Bannink, M. C. J. Smits, A. Van den Pol-Van Dasselaar, and I. Pinxterhuis. 2011. Intensive dairy production systems in an urban landscape, the Dutch situation. Livest. Sci. 139:122-134.

Wu, L., P. W. G. Groot Koerkamp, and N. W. M. Ogink. 2016. Temporal and spatial variation of methane concentrations around lying cubicles in dairy barns. Biosyst. Eng. 151:464-478. 